\title{
Foraging movements of emperor penguins at Pointe Géologie, Antarctica
}

\author{
Ilka Zimmer · Rory P. Wilson · Caroline Gilbert • \\ Michaël Beaulieu · André Ancel · Joachim Plötz
}

Received: 14 June 2007/Revised: 3 August 2007/Accepted: 7 August 2007

(C) Springer-Verlag 2007

\begin{abstract}
The foraging distributions of 20 breeding emperor penguins were investigated at Pointe Géologie, Terre Adélie, Antarctica by using satellite telemetry in 2005 and 2006 during early and late winter, as well as during late spring and summer, corresponding to incubation, early chick-brooding, late chick-rearing and the adult pre-moult period, respectively. Dive depth records of three post-egg-laying females, two post-incubating males and four late chick-rearing adults were examined, as well as the horizontal space use by these birds. Foraging ranges of chick-provisioning penguins extended over the Antarctic shelf and were constricted by winter pack-ice. During spring ice break-up, the foraging ranges rarely exceeded the shelf slope, although seawater access was apparently almost unlimited. Winter females appeared constrained in their access to open water but used fissures in the sea ice and expanded their prey search effort by expanding the horizontal search component underwater. Birds in spring however, showed higher area-restricted-search than did birds in winter. Despite different seasonal foraging strategies, chick-rearing penguins exploited similar areas as
\end{abstract}

I. Zimmer $(\bowtie) \cdot$ J. Plötz

Alfred Wegener Institute for Polar and Marine Research, PO Box 120161, 27515 Bremerhaven, Germany

e-mail: izimmer@awi-bremerhaven.de

\section{R. P. Wilson}

Institute of Environmental Sustainability,

School of Biological Sciences, University of Wales Swansea,

Singleton Park, SA2 8PP Swansea, Wales, UK

C. Gilbert · M. Beaulieu - A. Ancel

IPHC - Département Écologie, Physiologie et Éthologie, UMR7178 Centre National de la Recherche Scientifique and Université Louis Pasteur, 23 rue Becquerel,

67087 Strasbourg, France indicated by both a high 'Area-Restricted-Search Index' and high 'Catch Per Unit Effort'. During pre-moult trips, emperor penguins ranged much farther offshore than breeding birds, which argues for particularly profitable oceanic feeding areas which can be exploited when the time constraints imposed by having to return to a central place to provision the chick no longer apply.

Keywords Foraging distribution - Central-place forager . Emperor penguin - Area-restricted-search .

Foraging strategies

\section{Introduction}

During their breeding season, pelagic seabirds forage from a central place (sensu Orians and Pearson 1979) travelling outward to feeding patches, where their foraging behaviour is difficult, or impossible to observe. However, advances in solid-state technology in the form of animal-attached devices have done much to change this. There is now a suite of transmission and logging technologies available to help us examine the location and extent of feeding of seabirds (see Ropert-Coudert and Wilson 2005 for review).

The emperor penguin (Aptenodytes forsteri) is the largest (up to $40 \mathrm{~kg}$ mass, Williams 1995) and deepest diving of all breeding seabirds, feeding only at sea, with a maximum-recorded dive depth of $564 \mathrm{~m}$ (Wienecke et al. 2007). These extraordinary diving capabilities allow emperor penguins to forage deep in the open ocean and throughout the water column over the Antarctic shelf. Exploitation of prey at depth gives the emperor penguin access to a large water volume, which presumably helps counteract their low travelling speeds compared to volant seabirds (Meinertzhagen 1955; Wilson et al. 1989; 
Kooyman et al. 1992a; Weimerskirch et al. 1994b). A lower travelling speed compromises a breeding bird's ability to forage because it correspondingly reduces the range over which central place foragers may operate (Orians and Pearson 1979). This time spent foraging is determined by the necessary feeding frequency of the brood. The foraging efficiency achieved during the trip is constrained by prey encounter rate, which is itself affected by travelling speeds and depths (Ropert-Coudert et al. 2004).

The rate at which energy can be delivered to the brood, therefore, is dependent on these factors but also, critically, on the distance between foraging- and breeding sites (Weimerskirch et al. 1994a; Weimerskirch 1998; RopertCoudert et al. 2004). How far emperor penguins have to travel and whether they might feed over all, or simply part of, their foraging trips will likely depend on extrinsic conditions such as sea-ice cover and prey distribution, both vertically and horizontally. Indeed, observations at emperor penguin colonies have shown that foraging trips vary in duration as the breeding season goes on (Kirkwood and Robertson 1997a), with the suggestion being that this is brought about by changes in the environment. The complexity of environmental conditions, both biotic and abiotic, with which emperor penguins have to contend ultimately distil out into two major behavioural patterns which are expressed during foraging: (1) travelling behaviour, where birds move quickly and directly through regions inappropriate for foraging, and (2) searching behaviour, where a reduced rate of overall travel results from greater track tortuosity in regions where prey is most likely to be located (Wilson 1995; Leopold et al. 1996; Jaquet and Whitehead 1999; Nolet and Mooij 2002; Wilson 2002; Markman et al. 2004; Austin et al. 2006). The time allocated to each of these two behaviours results in a total foraging trip duration, which modulates the rate at which chicks can acquire food and thus grow appropriately.

At the colony of Pointe Géologie (Adélie Land) emperor penguins haunt areas of open water in the sea-ice such as polynias and light pack-ice zones during winter (Ancel et al. 1992; Rodary et al. 2000a). During summer, however, when sea-ice limitations diminish, their foraging extent is still unknown. From September on, when chicks become thermally independent, adults shuttle between the colony and the open water over about 100 days to forage. At this time each adult breeder may perform up to 8 or 9 foraging trips, lasting between 2 days and several weeks (Mougin 1966; Isenmann 1971; Offredo and Ridoux 1986; Kooyman and Kooyman 1995; Kirkwood and Robertson 1997a). The high energetic demands of adult penguins during the time that chicks are thermally independent (Robertson and Newgrain 1996) result from the birds having to acquire enough food for themselves as well as their brood in a period when much time and energy is invested in commuting between the central (breeding) place and the site of food acquisition. The situation is exacerbated because emperor penguins also have to gain enough body reserves to be able to moult (which lasts on average 30 days and during which no foraging occurs, e.g. Le Maho et al. 1976; Groscolas 1978). This occurs immediately after the chicks become fully independent.

The objectives of this study were: (1) to identify the foraging distribution of breeding emperor penguins from Pointe Géologie during winter, late chick-rearing and adult pre-moult periods, (2) to identify the moult location with a view to assessing how this location ties in with breeding and feeding constraints, (3) to examine depth utilisation of penguins during winter and late chick-rearing so as to (4) elucidate prey search strategies for the different stages of the birds' life cycle.

\section{Materials and methods}

Study colony, periods, instruments and fieldwork

The study was conducted at the Pointe Géologie colony $\left(66^{\circ} 40^{\prime} \mathrm{S}, 140^{\circ} 01^{\prime} \mathrm{E}\right)$ near Dumont d'Urville station; (1) during austral winter between the end of May and the beginning of September 2005 and (2) in spring and summer between the end of October 2005 and the end of January 2006.

During the first study in winter, three females and two males were equipped during the pairing period (between 20 April and 11 May) with satellite transmitters to track their foraging trips and archival tags to record their diving behaviour. The satellite transmitters (Sirtrack, New-Zealand, $13 \times 5 \times 3 \mathrm{~cm}$ ) weighed $230 \mathrm{~g}$ and had a $16 \mathrm{~cm}$ antenna (angled at $60^{\circ}$ and facing backwards). They transmitted with a pulse repetition rate of $90 \mathrm{~s}$, and were duty cycled to be $6 \mathrm{~h}$ on and $6 \mathrm{~h}$ off. The time depth recorders (Mk9, Wildlife Computers, USA, $6.7 \times 1.7 \times 1.7 \mathrm{~cm}, 0.5 \mathrm{~m}$ depth resolution, 0 to $1,000 \mathrm{~m}$ depth range) weighed $30 \mathrm{~g}$, had a memory of 16 Mbytes and were set to record every $5 \mathrm{~s}$.

For the second study period, during late chick-rearing, birds were either equipped on their return from sea before reaching the colony, or after they had fed the chick and were about to leave the colony again. Several couples were colour marked (using Nyanzol) during the pairing period in order to monitor breeding success. We attempted to choose successful breeders with a healthy chick among these marked birds for device equipment. Two types of Argos transmitter were used: between the 31 October and the 1 December; fifteen adult emperor penguins were equipped either with a conventional satellite transmitter (Spot5, 
Wildlife Computers, USA, $7.1 \times 3.4 \times 2.6 \mathrm{~cm}, 78 \mathrm{~g}$ ) or a device that combined an Argos transmitter with an archival tag (Splash, Wildlife Computers, USA, $7.8 \times 5.0 \times 2.3 \mathrm{~cm}$, $105 \mathrm{~g}, 0.1 \mathrm{~m}$ depth resolution, $0-1,000 \mathrm{~m}$ depth range, memory-14 Mbytes, set to record every $2 \mathrm{~s}$ ). Six Spot5 tags were used to measure foraging tracks during late chick-rearing and during the pre-moult stage. The further deployment of five Splash tags allowed additional dive data records. Spot5 and Splash tags had 17 and $19 \mathrm{~cm}$ long antennae, respectively, that projected out at the back of the transmitters (angled at $60^{\circ}$ and $65^{\circ}$, respectively, and facing backwards) both transmitting at $90 \mathrm{~s}$ intervals continuously but limited to a maximum of 320 transmissions per day.

In a third study, five birds remained equipped (Spot5 or Splash) beyond the chick-rearing period to enable us to record pre-moult trips. Here, we expected that the start of the moult would be the last position recorded before the loggers fell off with the old plumage.

The frontal area of $15 \mathrm{~cm}^{2}$ (Sirtrack satellite transmitter) constituted about $2.6 \%$ of a $24 \mathrm{~kg}$ penguin's cross-sectional area (Wienecke and Robertson 1997), being only 0.5, 1.5 and $2 \%$ for MK9, Spot5 and Splash, respectively. To minimize drag (Bannasch et al. 1994) the devices were attached to the lower back feathers using either glue and hose clamps or Tesa tape (Wilson et al. 1997).

Sea-ice concentration maps were provided by the Advanced Microwave Scanning Radiometer for EOS (AMSR-E) and bathymetric data were derived from the ETOPO 1 min gridded evaluation database (GEBCO 1-min global bathymetric grid).

Analysis of transmitted location and archival dive data

Argos satellite records (CLS Argos, Toulouse, France) were classified according to the size of the error radius of the location and the number of signals received by the satellite during a pass. Satellite records were processed by the company OPTIMARE (Bremerhaven, Germany). Data were speed-filtered by comparison of two fixes in succession. The mean speed of travel was calculated by dividing the distance by the time difference between two fixes. When this value exceeded a predetermined maximum speed the point was eliminated from the dataset. We set the maximum speed at $15 \mathrm{~km} \mathrm{~h}^{-1}$ (Wienecke and Robertson 1997), which is slightly higher than the $14.4 \mathrm{~km} \mathrm{~h}^{-1}$ estimated by Kooyman et al. (1992b) for emperor penguins diving under the ice.

Following the distance classifications of Wienecke and Robertson (1997), the maximum distances from the nesting location at Pointe Géologie were measured in a straightline between the colony and the penguin's most distant position. Minimum total travelling distances were considered to be the sum of all distances between valid locations.

\section{Depth analysis}

Depth data were corrected for surface drift in depth values recorded at the water's surface (which varied by $\pm 2 \mathrm{~m}$ ) using special software (MT-dive; Jensen Software, Kiel, Germany). This software analysed all dives sequentially, writing, dive per dive, a number of defined parameters into an output file. These were: the time of the dive initiation, the overall dive duration, the maximum depth reached during the dive, the descent-, bottom-, and ascent-phase duration, the vertical velocities during the descent, bottom and ascent phases, the number of rapid succession short ascent/descent phases during the bottom phase, and the post-dive interval.

All dives deeper than $2 \mathrm{~m}$ were considered as proper dives. The bottom phase, during which penguins are most likely to hunt (Chappell et al. 1993; Wilson et al. 1995) and appear to capture most of their prey (Takahashi et al. 2004; Ropert-Coudert et al. 2006; Bost et al. 2007), was defined by three conditions; it could only occur (1) at depths $>85 \%$ of the maximum depth of the dive (cf. Kirkwood and Robertson 1997b), (2) if it was bounded by two points of inflection in the rate of change of depth and (3) if the overall rate of change of depth for the whole of the putative bottom period did not exceed $0.2 \mathrm{~ms}^{-1}$ (Rodary et al. 2000a). Short ascent/descent phases $>2 \mathrm{~m}$ during the bottom phase of a dive were quantified according to the number of points of inflection (SPI) during the ascents and descents. Two or three SPI were described as a "wiggle". Such wiggles result in the capture of a single prey item pursued by Magellanic penguins Spheniscus magellanicus during the bottom phases of their dives (Fig. 1, cf. Simeone and Wilson 2003). They are also considered to be generally indicative of prey pursuit in penguins (Kirkwood and Robertson 1997b; LunaJorquera and Culik 1999; Hull 2000; Rodary et al. 2000b; Tremblay and Cherel 2000; Takahashi et al. 2004). Thus, although we could not derive absolute numbers of prey caught using the methodology, we considered that the number of wiggles occurring in the bottom phase of emperor penguin dives to be approximately linearly related to the number of prey caught. This SPI estimate was divided by the duration of the bottom phase to derive an estimate of prey abundance via 'catch-per-unit effort' (CPUE). Again, although our CPUE figures cannot give absolute abundance indices, higher CPUE values should generally relate to more abundant prey and vice versa.

To examine how emperor penguins allocate their time to foraging in certain areas, we examined location and depth data recorded for full foraging trips in winter $(n=5)$ and 
(a)

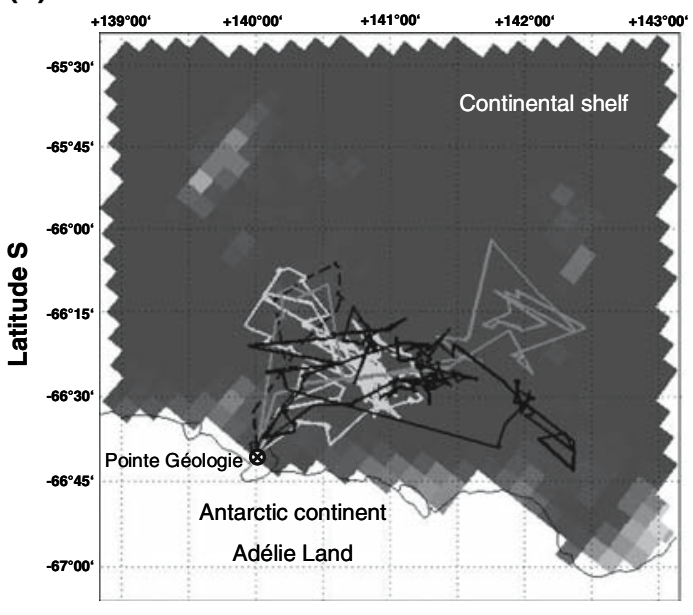

Longitude $\mathrm{E}$

(b)
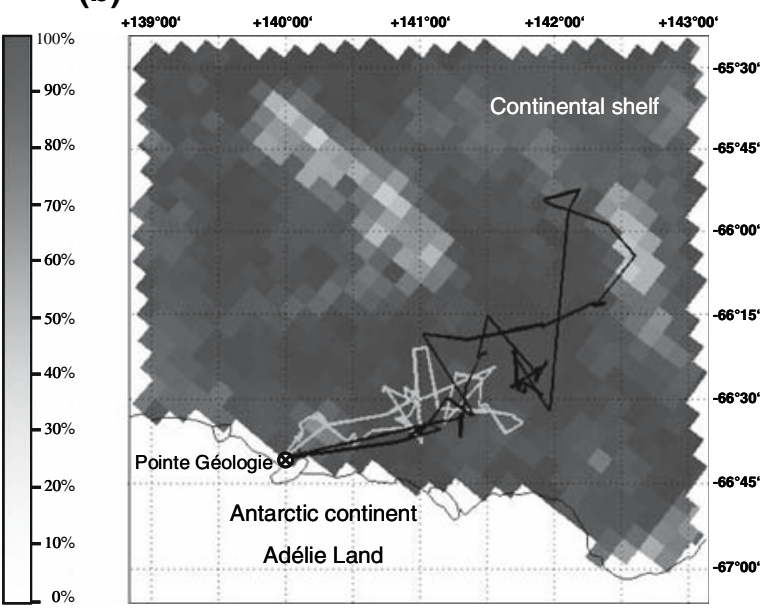

Fig. 1 Movements of a three females (a second trip recorded for female F-3a, see Table 1, is dashed) and $\mathbf{b}$ two males over the continental shelf of Adélie Land, monitored by satellite during winter between 15th May and 30th August 2005. Sea-ice data are displayed in percentage from 0 to $100 \%$ of ice cover provided by AMSR-E for a the 15 July 2005 and $\mathbf{b}$ the 2 August 2005 during late chick-rearing $(n=4)$. Foraging trips were cut into sections corresponding to periods in which a penguin spent a total $\geq 100$ min underwater (although the precise duration varied according to the timing of satellite fixes). Two foraging parameters were defined relating to both the vertical and the horizontal movement. The extent of vertical movement (here termed vertical extent-VE) was defined by summing maximum depths from all dives between two defined time intervals so that:

$\mathrm{VE}=\Sigma 2 \times$ maximum dive depths

(units $\mathrm{m}$ ) over a specified period. Here, the doubling of maximum depths takes into account both the descent and ascent of the dives.

The horizontal movement was divided into two elements (1) the overall horizontal movement within any dive and (2) the tortuosity of the horizontal movement. In order to highlight the degree of the horizontal movement within any dive, cognisance needs to be taken of the extent of the vertical contribution in the dive (see VE above). Based on the fact that penguins travel at a relatively constant speed when underwater (Wilson et al. 2002), the extent of horizontal movement within any one dive can be alluded to via the normal swimming speed multiplied by the dive duration divided by the vertical extent for that dive. Thus, over a defined time period, within which numerous dives are conducted, the horizontal extent (HE):

$\mathrm{HE}_{\text {underwater }}=\Sigma$ Dive durations $\times$ Swim speed $/ \mathrm{VE}$,

(non-dimensional units) where a normal swim speed of $3 \mathrm{~ms}^{-1}$ was taken as standard (Kooyman et al. 1992b).
Although this speed figure is based on rather observations from non-breeding birds, it is unlikely to differ greatly from that of foraging birds since penguins generally travel at their lowest cost of transport (Culik et al. 1994), showing remarkably little variation. Any errors in this figure will be consistent across groups and thus affect derived parameters similarly. Note that simple subtraction of the vertical extent from the total distance covered during a dive (nominally derived via the swim speed multiplied by the dive duration) does not take into account how overall distance, vertically travelled distance and horizontally travelled distance change with varying dive angles. For this reason, we opted for a simple ratio, with higher values indicating a greater proportion of the time underwater being dedicated to horizontal travel.

The horizontal tortuosity (HT) was derived by considering the extent of the HE in relation to the straight-line distance between two defined points in time:

$\mathrm{HT}=\mathrm{HE}_{\text {underwater }} /$ Straight - line distance,

(units $\mathrm{m}^{-1}$ ), where the straight-line distance corresponded to the distance between two adjacent PTT fixes. However, this definition was standardized to encompass a defined period of a foraging trip (see above). For this, the sum of the straight-line distances between PTT fixes was taken to represent the overall distance.

Two other measures used to quantify foraging activity over a trip were:

(1) the "Area-Restricted-Search Index" (ARS-I), which was determined by dividing the total distance spent travelling underwater over a defined time interval 
(given by the duration underwater multiplied by the normal swimming speed of $3 \mathrm{~ms}^{-1}$ ) by the straightline distance travelled during that period (see above) as follows:

$$
\begin{aligned}
& \text { ARS - I = Total distance } \text { underwater }_{\text {/ }} \\
& \text { Straight }- \text { line distance }
\end{aligned}
$$

(non-dimensional units). Here, high values indicate high tortuosity (both vertical and horizontal).

(2) the CPUE (SPI $\min ^{-1}$ ), here derived by dividing the number of points of inflection in the bottom phases of dives, by the total time spent underwater for that defined time interval (see above).

Sexes

The two sexes of adult emperor penguins in winter adopt different roles during incubation and chick brooding during which time only one member of a pair gathers food at sea. During late chick-rearing, however, when chicks are thermally independent, adults shuttle almost continuously between the colony and the sea to forage. At this time the sex of inbound penguins could only be (sometimes) determined by voice differentiation by us (Jouventin 1982; Robisson 1992).

The pattern of foraging during trips at sea will be discussed for post-egg-laying females, post-incubating males and adults of both sexes during late chick-rearing with cognisance of the variability of the environmental conditions (such as sea-ice cover and seawater access) for these periods. Data of post-egg-laying females and post-incubating males were combined to compare winter-foraging birds with spring-foraging birds.

\section{Statistics}

In order to compare foraging activity parameters for penguin groups with regard to the trip duration, individual foraging trip durations (time at sea) were all taken to add up to $100 \%$ and the various trip sections (see above) within these transformed accordingly (cf. Ropert-Coudert et al. 2004). Data are presented as means, averaged over each $10 \%$ interval of foraging trip duration. ARS-I and CPUE mean values over foraging trips were defined to be high when they exceeded $60 \%$ of the individual parameter maximum. Mean values are presented \pm 1 standard error (SE). Significant differences between winter-foraging females and winter-foraging males or winter-foraging birds (both sexes) and spring-foraging birds were tested for all values in considered groups without regard to the trip duration by a parametric unpaired $t$ test $(t)$ or the nonparametric Mann-Whitney rank sum test $(U)$, if data did not pass the Kolmogorov-Smirnov test $(P \leq 0.05)$ for normal distribution. The significance level was $\alpha \leq 0.05$. Statistic tests were performed with SigmaStat version 3.5 (Systat Software, Point Richmond, USA).

\section{Results}

Winter (incubation and chick-provisioning)

\section{Foraging distribution}

The emperor penguins equipped in winter foraged exclusively over the coastal shelf. On their departure from Pointe Géologie in May, the three post-egg-laying females headed north-east of the colony where sea-ice images showed closed pack-ice of up to $100 \%$ (Fig. 1a). They travelled for 4-7 days (mean: $6 \pm 1$ day) across $22-96 \mathrm{~km}$ (mean: $56 \pm 21 \mathrm{~km}$ ) of fast-ice before entering the sea to forage. After their last dive at the end of the foraging trip, the birds travelled 1-4 days (mean: $2 \pm 1$ day) across the fast-ice to return to the colony. The walking distances could not be calculated due to a lack of positional fixes at the end of the trip. The three females' complete foraging trips lasted for $72 \pm 7$ days (range: 59-79 days, Table 1) of which $65 \pm 7$ days were spent actually gathering food (range: 51-72 days, resting periods on ice floes when the birds were ostensibly at sea were included here). Mean distance travelled over a foraging trip averaged $927 \pm 175 \mathrm{~km}$ (range: $582-1,149 \mathrm{~km}$ ) while the mean maximum distance to the colony was $94 \pm 16 \mathrm{~km}$ (range: 62-116 km, Table 1).

The two equipped male penguins headed north-east after the incubation fast. One foraged where satellite images showed areas of open pack-ice and the other in open pack-ice and a polynia (Fig. 1b). Their complete foraging trips lasted for $24 \pm 5$ days (range: 19-29 days, Table 1) of which $22 \pm 5$ days were spent gathering food (range: 17-27 days, resting periods on ice floes when the birds were ostensibly at sea were included here). Males travelled mean foraging trip distances of $521 \pm 62 \mathrm{~km}$ (range: $459-582 \mathrm{~km}$ ) while the mean maximum distance to the colony was $106 \pm 28 \mathrm{~km}$ (range: $78-133 \mathrm{~km}$, Table 1). Both males travelled for two days before undertaking the first dive but covered different distances during that time, walking on the fast ice distances of 54 and $1 \mathrm{~km}$.

The second winter foraging trip conducted by one of the three females (F-3a, Table 1, Fig. 1a) was recorded due to a failed recapture after the first return to the colony. F-3a restarted after 20 days of parental care and travelled for 
Table 1 Aptenodytes forsteri. Summary of foraging data on monitored females and males in winter, birds in spring and summer (both sexes) at Pointe Géologie in 2005/2006. Emperor penguins were equipped with satellite transmitters

\begin{tabular}{|c|c|c|c|c|c|}
\hline Penguins & $\begin{array}{l}\text { Foraging trip } \\
\text { records }(N)\end{array}$ & $\begin{array}{l}\text { Trip dates } \\
\text { (depart-return) }\end{array}$ & $\begin{array}{l}\text { Trip duration } \\
\text { (days) }\end{array}$ & $\begin{array}{l}\text { Distance } \\
\text { travelled }(\mathrm{km})\end{array}$ & $\begin{array}{l}\text { Maximum distance } \\
\text { To colony }(\mathrm{km})\end{array}$ \\
\hline Winter-foraging females & 3 & 15 May-2 Aug & & & \\
\hline Median (range) & & & $79(59-79)$ & $1,050(582-1,149)$ & $104(62-116)$ \\
\hline Mean $( \pm$ SE) & & & $72 \pm 7$ & $927 \pm 175$ & $94 \pm 16$ \\
\hline F-3a trip2 & 1 & 4 Aug-14 Aug & 10 & 174 & 68 \\
\hline Winter foraging males & 2 & 24 Jul-30 Aug & & & \\
\hline Median (range) & & & $25(19-29)$ & $521(459-582)$ & $105(78-133)$ \\
\hline Mean $( \pm$ SE) & & & $24 \pm 5$ & $521 \pm 62$ & $106 \pm 28$ \\
\hline Spring-foraging birds (both sexes) & 21 & 31 Oct-17 Dec & & & \\
\hline Median (range) & & & $8(2-19)$ & $397(81-859)$ & $89(21-163)$ \\
\hline Mean $( \pm$ SE) & & & $7 \pm 1$ & $387 \pm 48$ & $85 \pm 8$ \\
\hline Summer-foraging birds (both sexes) & 5 & 22 Nov-20 Jan & & & \\
\hline Median (range) & & & $42(31-54)$ & $3,056(1,762-3,686)$ & $649(425-838)$ \\
\hline Mean $( \pm$ SE) & & & $42 \pm 5$ & $2,862 \pm 345$ & $647 \pm 72$ \\
\hline
\end{tabular}

10 days, of which 7 days were spent foraging at sea. This foraging trip covered a travelling distance of $174 \mathrm{~km}$, reaching a maximum distance of $68 \mathrm{~km}$ to the colony (Table 1).

\section{Diving behaviour}

Depth data recorded for the three post-egg-laying females and the two post-incubating males totalled 19,082 dives $(14,662$ by females and 4,420 by males, Table 2$)$. In winter males dived deeper than females $(69.5 \pm 10.8$ for males and 55.6 $\pm 3.0 \mathrm{~m}$ for females; $U=28,098,776, P<0.001$; Fig. 2, Table 2) showing an absolute maximum depth of
438.4 vs. $338.8 \mathrm{~m}$ ). While at sea, the females and males had days of no water entry. The three females took more of these "rest days" (sensu Kirkwood and Robertson 1997b) than did the two males and, therefore, foraged on proportionally fewer of their days at sea $(84.1 \pm 3.2$ vs. $\left.98.2 \pm 1.9 \% ; t_{3}=-3,194, P=0.05\right)$. On average, winterforaging birds (sexes combined) foraged $91.2 \pm 7.1 \%$ of their days at sea.

Mean and maximum dive durations were both higher for males than for females at $3.1 \pm 0.4$ versus $2.5 \pm 0.1 \mathrm{~min}$ $(U=26,697,777, P<0.001)$ and 16.1 versus $12.2 \mathrm{~min}$, respectively (Table 2 ). The two males dived for $5.2 \pm 0.3 \mathrm{~h} \mathrm{day}^{-1}$ (range: $2.1-7.8 \mathrm{~h} \mathrm{day}^{-1}$ ) from $07 \mathrm{~h} 11$ to $18 \mathrm{~h} 16$ whereas the three females spent $3.5 \pm 0.2 \mathrm{~h}^{\text {day }^{-1}}$

Table 2 Basic dive features of nine emperor penguins at Pointe Géologie, Adélie Land, in winter and spring 2005, recorded with archival tags and satellite transmitters

\begin{tabular}{|c|c|c|c|c|c|}
\hline Penguins & $\mathrm{N}$ dives & $\begin{array}{l}\text { Max. dive } \\
\text { depth (m) }\end{array}$ & $\begin{array}{l}\text { Mean max. } \\
\text { dive depth (m) }\end{array}$ & $\begin{array}{l}\text { Max. dive } \\
\text { duration (min) }\end{array}$ & $\begin{array}{l}\text { Mean dive } \\
\text { duration (min) }\end{array}$ \\
\hline Winter-foraging females & 13,605 & & & & \\
\hline Grand mean $( \pm$ SE) & & $321.9 \pm 19.8$ & $55.6 \pm 3.0$ & $11.2 \pm 0.8$ & $2.5 \pm 0.12$ \\
\hline F-3aTrip2 & 1,057 & 242.5 & $47.3 \pm 1.8$ & 10.3 & $2.7 \pm 0.02$ \\
\hline Winter-foraging males & 4,420 & & & & \\
\hline Grand mean $( \pm \mathrm{SE})$ & & $426.9 \pm 11.6$ & $69.5 \pm 10.8$ & $14.0 \pm 2.2$ & $3.1 \pm 0.35$ \\
\hline Winter-foraging birds (both sexes) & 19,082 & & & & \\
\hline Grand mean $( \pm \mathrm{SE})$ & & $343.7 \pm 30.6$ & $58.8 \pm 4.7$ & $12.0 \pm 0.9$ & $2.7 \pm 0.2$ \\
\hline Spring-foraging birds (both sexes) & 5,466 & & & & \\
\hline Grand mean $( \pm \mathrm{SE})$ & & $328.0 \pm 42.2$ & $99.0 \pm 7.2$ & $10.5 \pm 0.7$ & $4.1 \pm 0.12$ \\
\hline
\end{tabular}

Mean values are given $\pm 1 \mathrm{SE}$ 


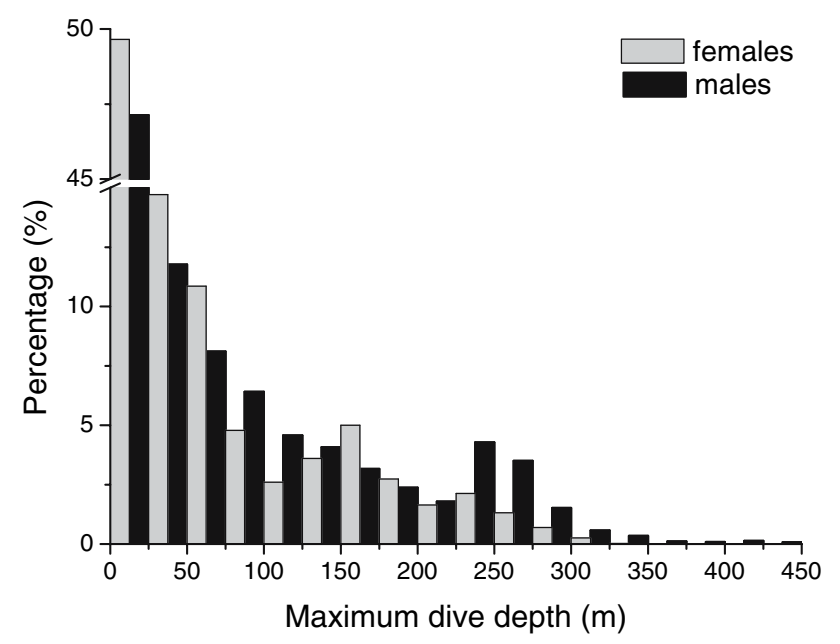

Fig. 2 Frequency distribution of maximum dive depths from foraging emperor penguin females and males, monitored in winter 2005 at Pointe Géologie, Adélie Land

(range: 0.4-6.3 $\mathrm{h} \mathrm{day}^{-1}$ ) in the water, all of which occurred from $08 \mathrm{~h} 06$ to $17 \mathrm{~h} 27$ (solar time) and showed higher dive frequencies per day than females $(101 \pm 5$ vs. $85 \pm 3$ dives day $\left.^{-1} ; U=5,546.5, P=0.004\right)$.

\section{Allocation of time during foraging}

Altogether, winter-foraging birds showed maximum horizontal tortuosity between 0 and $10 \%$ of the trip duration (Fig. 3a) and maximum vertical effort between 60 and $70 \%$ of the time into the trip (Fig. 3b). Horizontal tortuosity was significantly higher for females than for males $(U=3,324$, $P=0.05)$, whereas the vertical extent was significantly higher for males than for females $(U=4,591, P=0.028)$.
Measures for the overall foraging activity

The area-restricted-search index (ARS-I) showed highly variable values over the course of the foraging trip (Fig. $4 \mathrm{a}$, b) as did the CPUE (Fig. 4c).

Winter-foraging birds (both sexes) showed maximum prey search activity between 70 and $80 \%$ of trip duration (Fig. 5a) and maximum CPUE between 60 and $70 \%$ of the time into the trip. There was no significant difference of the ARS-I between females and males $(U=2,824, P=0.677)$. The CPUE, however was higher for males than for females $(U=2,173, P=0.009)$.

Spring (chick provisioning)

\section{Foraging distribution}

The emperor penguins equipped during the late chickrearing period ( $n=10 ; 21$ foraging trips) centred their foraging activity in shelf waters north-east of the colony covering an area of about $25,000 \mathrm{~km}^{2}$ (Fig. 6). Foraging trips lasted for 2-19 days (mean: $7 \pm 1$ days) and rarely went beyond the slope region. The trip lengths of $81-$ $859 \mathrm{~km}$ (mean: $387 \pm 48 \mathrm{~km}$ ) reached individual maximum distances of 21-163 km (mean: $85 \pm 8 \mathrm{~km}$ ) from the colony (Table 1). The penguins travelled up to $50 \mathrm{~km}$ per day.

\section{Diving behaviour}

Depth data recorded for four adults comprised 5,466 dives (Table 2). Mean maximum dive depth of spring-foraging birds was higher than for winter-foraging birds $(99.0 \pm 7.2$ vs. $58.8 \pm 4.7 \mathrm{~m}, U=34,031,782, P<0.001)$ although the ranges of maximum dive depth of both groups were (a)

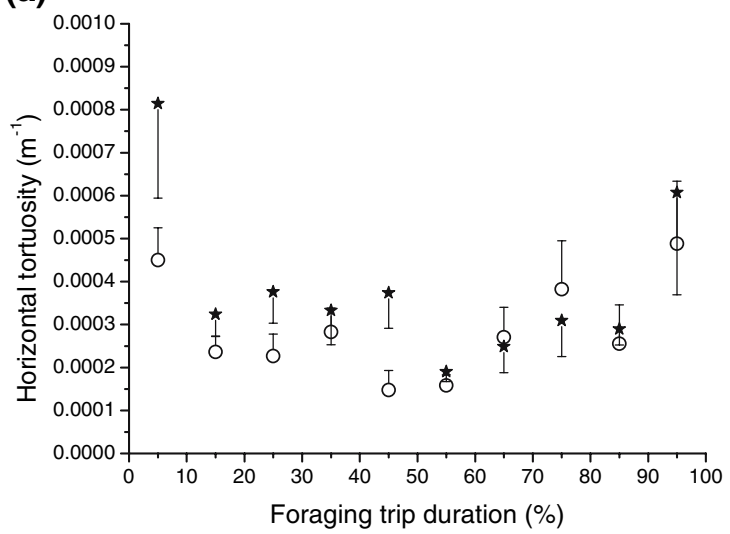

(b)

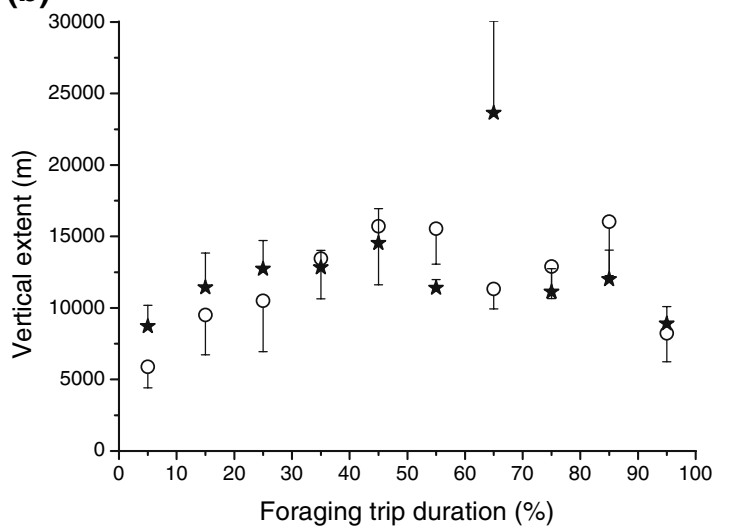

Fig. 3 a Horizontal tortuosity and $\mathbf{b}$ vertical extent of emperor penguins foraging during winter (filled star $n=5)$ and spring (open circle, $n=4)$. Data are presented as means with standard error $(S E)$ per $10 \%$ classes over foraging trip duration 

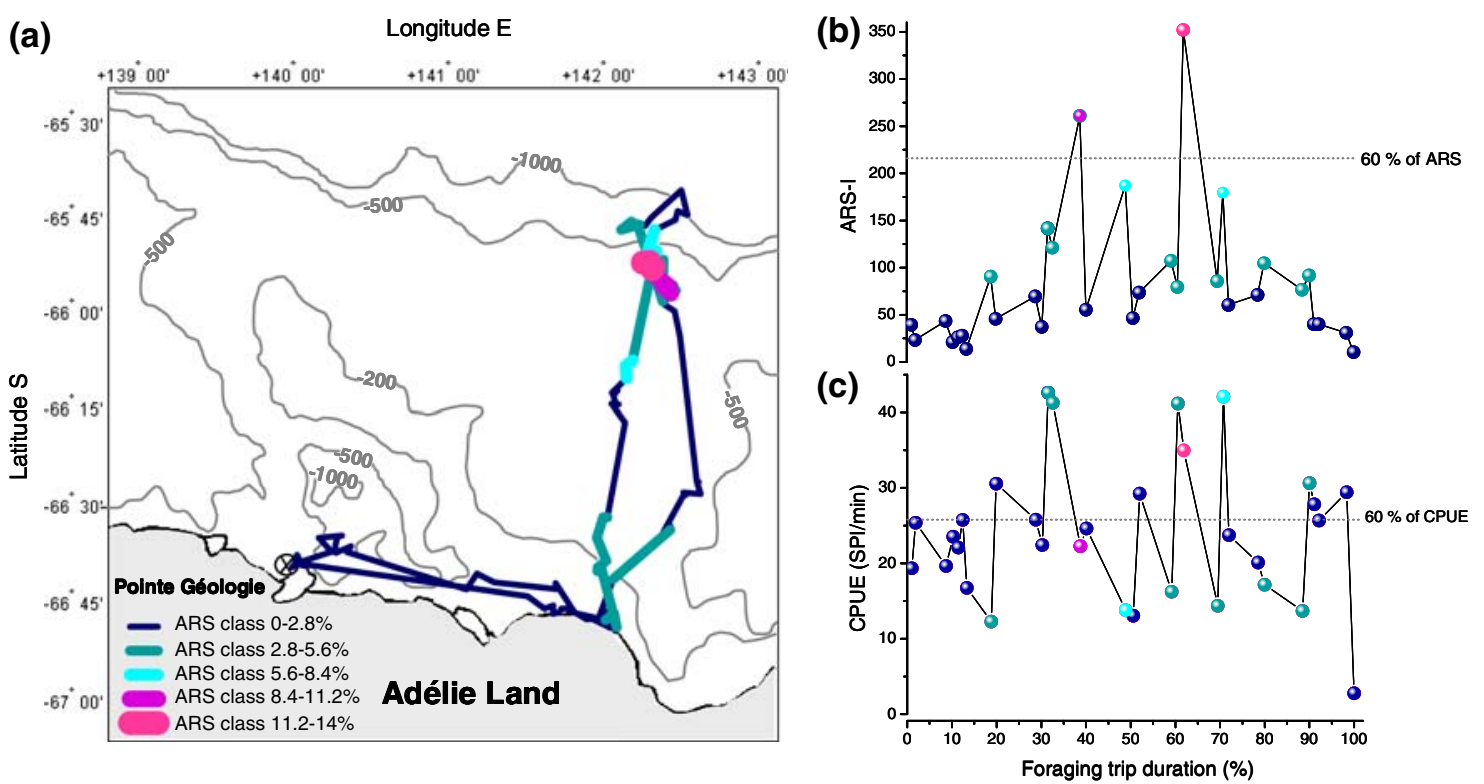

Fig. 4 a Area-restricted-search index $(A R S-I)$ in percent of a breeding emperor penguin in spring over a complete foraging trip at Pointe Géologie over the Antarctic shelf and b ARS-I and $\mathbf{c}$ catch per unit effort (CPUE, SPI $\mathrm{min}^{-1}$ ) as they vary with foraging trip duration. ARS-I intensity (in percent) is displayed in $\mathbf{a}, \mathbf{b}$ and $\mathbf{c}$ by

(a)

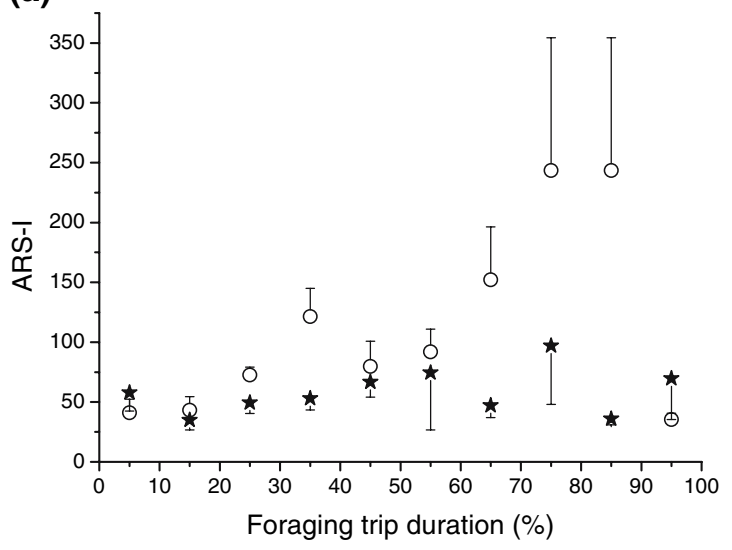

Fig. 5 a Area-restricted-search index $(A R S-I)$ and b catch per unit effort (CPUE, SPI $\mathrm{min}^{-1}$ ) of emperor penguins foraging during winter (filled star $n=5$ ) and during spring (open circle, $n=4$ ). Data are

almost identical (Table 2). In contrast to winter-foraging birds, the spring-foraging penguins did not take any restdays. Mean dive duration for spring-foraging birds was $4.1 \pm 0.1 \mathrm{~min}$ while maximum dive durations ranged from 9.0 to $13.0 \mathrm{~min}$ (Table 2). Spring-foraging birds showed a higher dive frequency than winter-foraging birds $(126 \pm 15$ vs. $91 \pm 5$ dives day $\left.^{-1}, U=1,874, P<0.001\right)$ and spent more time underwater $\left(8.7 \pm 1.1\right.$ vs. $4.2 \pm 0.4 \mathrm{~h} \mathrm{day}^{-1}$, $U=932, P<0.001)$ at any hour of the day. Seventy-six percent of dives occurred from $03 \mathrm{~h} 00$ to $17 \mathrm{~h} 00$ solar time. different colour marks that are explained in a. ARS-I b and CPUE $\mathbf{c}$ values were defined as maxima when exceeding $60 \%$ of the individual parameter maximum. a Shelf bathymetry was derived from the ETOPO 1 min gridded evaluation database (GEBCO 1-min global bathymetric grid)

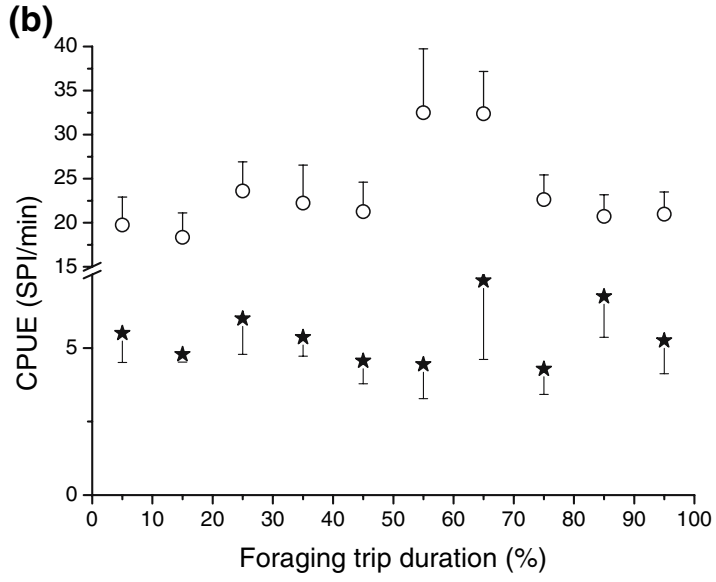

presented as means with standard error $(S E)$ per $10 \%$ classes over foraging trip duration

\section{Allocation of time during foraging}

Maximum horizontal tortuosity of spring-foraging birds occurred between 90 and $100 \%$ of trip duration (Fig. 3a) and maximum vertical effort between 80 and $90 \%$ of the time into the trip (Fig. 3b). There was no significant difference in either the horizontal tortuosity $(U=9,750$, $P=0.105)$ or the vertical effort $(U=9,496, P=0.223)$ between spring- and winter-foraging birds. Compared to winter females, however, spring-foraging birds showed a 
Fig. 6 Foraging trips $(n=21)$ of emperor penguins $(n=10)$ distributed over the Antarctic shelf of Adélie Land, monitored by satellite during late chickrearing between 31 October and 17 December 2005. Shelf slope off the Adélie Land coast as calculated from ETOPO1 min gridded evaluation database (GEBCO 1-min global bathymetric grid)

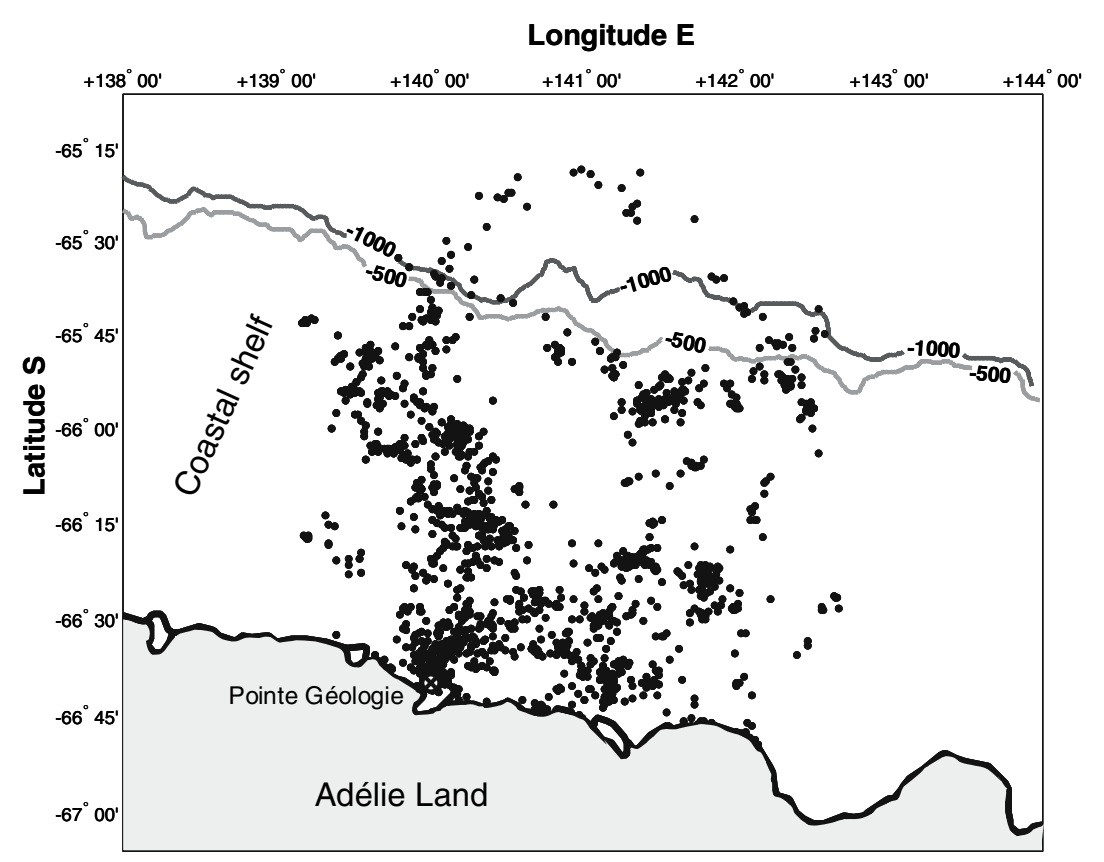

significantly lower investment in horizontal tortuosity $(U=7,153, P=0.0042)$.

\section{Measures for the overall foraging activity}

The maximum search behaviour occurred between 70 and $90 \%$ of trip duration (Fig. 5a) and the maximum CPUE occurred between 50 and $60 \%$ of the time into the trip (Fig. 5b). Spring-foraging birds showed a significantly higher ARS-I $(U=5,524, P<0.001)$ as well as a higher CPUE $(U=984, P<0.001)$ than winter-foraging birds. The latter significance concerning the CPUE, however, may be partially explained by the higher recording frequency of $2 \mathrm{~s}$ in spring compared to $5 \mathrm{~s}$ in winter.

\section{Summer (pre-moult)}

\section{Foraging distribution}

Five emperor penguins remained equipped from the breeding season right through into the moult. When leaving the colony after breeding, these birds headed north into the open ocean and dispersed widely to forage over deep water up to $660 \mathrm{~km}$ off the Adélie Land before turning back towards the Antarctic coast (Fig. 7). During this pelagic phase the trips lasted on average $42 \pm 5$ days (range: $31-$ 54 days) and birds covered a total mean distance of $2,862 \pm 345 \mathrm{~km}$ (range: $1,762-3,686 \mathrm{~km}$ ) with a maximum distance of $647 \pm 72 \mathrm{~km}$ (range: $425-838 \mathrm{~km}$ ) from the colony (Table 1). The last positions of the five equipped penguins were recorded between 31 December 2005 and 20 January 2006 (Fig. 7).

After being equipped in early November 2005, four birds never returned to the colony. As non-breeders or unsuccessful breeders, they spent their time at sea (Fig. 8). Nevertheless, their travelling routes were similar to those of the pre-moult, previously breeding birds heading into the same moulting areas (Figs. 6, 7) with last positions being recorded between 21 December 2005 and 11 January 2006.

\section{Discussion}

Accuracy of the methods

Although air-breathing divers have to surface frequently during foraging, these resting periods vary greatly in length over the foraging trip. This affects the likelihood of obtaining a satellite fix as well as the potential quality of any given fix because satellite uplinks can only occur when the PTT is in air. In addition, the likelihood of signal transmission depends on the number of satellite passes over the PTT location, which varies with latitude, and is, in any event, not constant per unit time (Georges et al. 1997). Finally, the manner in which the tag is attached to the animal may also affect transmission properties. All these factors account for the variability in timing and quality of location fixes.

The travelled distance of a penguin between two valid position fixes was considered to be the minimum straightline distance. As the number of positional fixes increases per unit time, the calculated travel distance will tend to 
Fig. 7 Movements of five emperor penguins before the adult moult in the Dumont durville Sea, monitored by satellite between 22 November 2005 and 20 January 2006. Sea-ice data are displayed in percentage from 0 to $100 \%$ of ice cover provided by AMSR-E for the 20 January 2006. Last at-sea positions are marked by a star
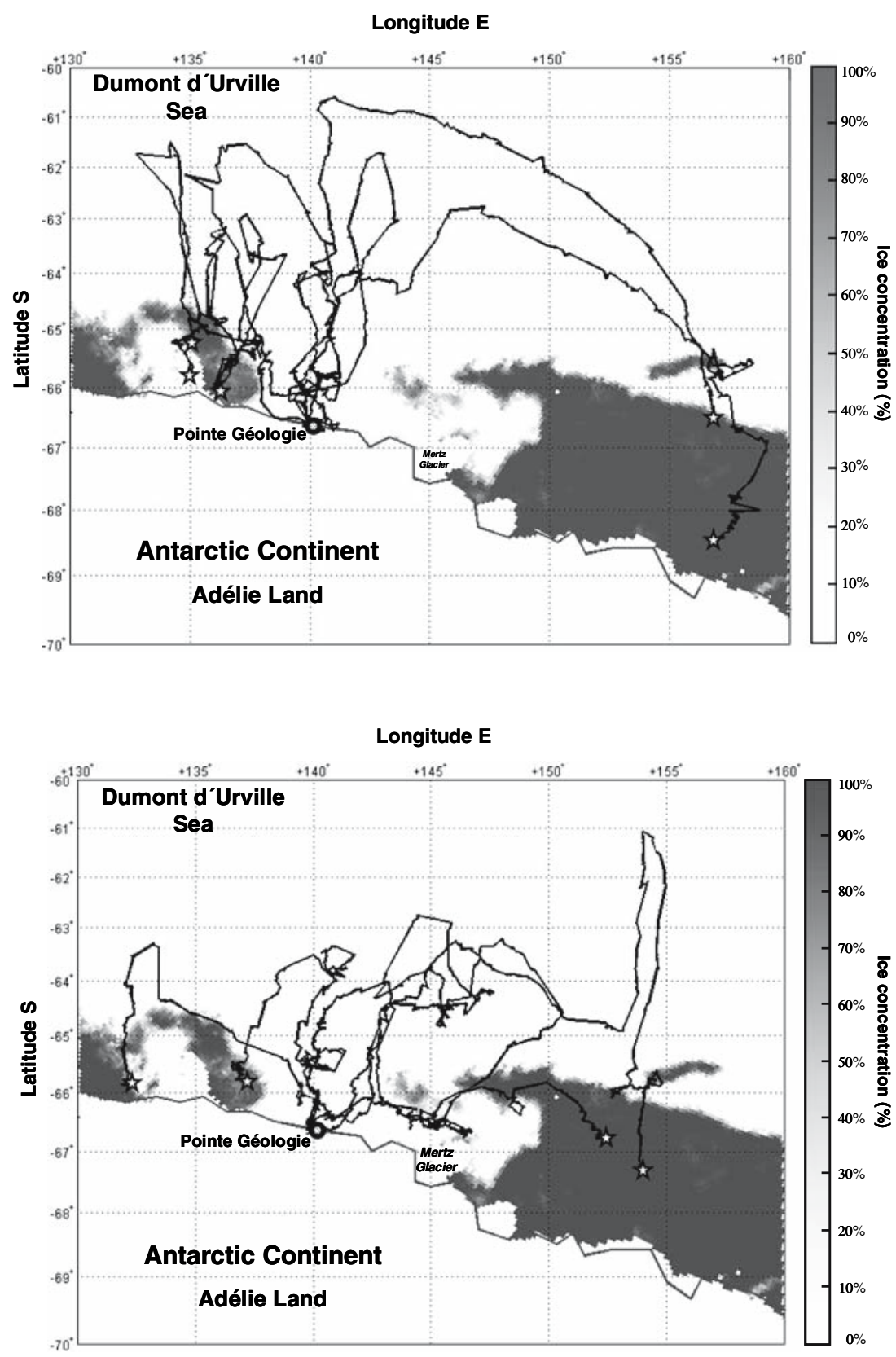

Fig. 8 Movements of four nonor unsuccessful breeding emperor penguins, before the adult moult in the Dumont durville Sea, monitored by satellite between 2 November 2005 and 11 January 2006. Sea-ice data are displayed in percentage from 0 to $100 \%$ of ice cover provided by AMSR-E for the 20 January 2006. Last at-sea positions are marked by a star
Winter (incubation and chick-provisioning)

increase because the deviations from a straight-line course will be incorporated. Since the number of valid positions over a foraging trip length varied, analyses were classified into defined time periods spent underwater. This meant that sections of comparable foraging activity (the time spent underwater) could be compared. However, the non-standardized way in which Argos positional fixes were acquired means that, even so, we had to consider different time periods and numbers of valid positions per defined trip section. The resolution of penguin foraging tracks and the analysis of horizontal tortuosity need to bear this in mind although we expect that our approach should broadly highlight trends.

\section{Movement at sea}

When female penguins conducted their first foraging trip after egg-laying (May-July) the sea-ice extension off the Adélie Land coast was higher than at any other time during the emperor penguin breeding cycle (Metéo station of DDU and AMSR-E - Sea-Ice concentration maps). The female foraging trip length was about two months in winter (56-79 days), which appears typical for this species (Prévost 1961; Wienecke and Robertson 1997). This gives the birds ample time to move far from the colony. Despite 
this, the penguins' winter foraging range in our study was restricted to cracks and holes in the pack-ice, as has been reported in previous studies (Ancel et al. 1992; Kirkwood and Robertson 1997b; Rodary et al. 2000a). Trip durations of 56-79 days partially confirmed earlier observations for this colony (Prévost 1961) whereas females at Auster colony returned after 67-96 days to their breeding site (Wienecke and Robertson 1997). The foraging distribution within $120 \mathrm{~km}$ of the breeding colony at Pointe Géologie was similar to Auster females but, however, females at Auster travelled more than twice the distance during foraging trips compared to females from Pointe Géologie (mean $2617 \pm 198 \mathrm{~km}$ at Auster vs. $927 \pm 175 \mathrm{~km}$ at Pointe Géologie).

In late July, when male penguins moved to sea after their long incubation fast, sea-ice satellite images indicated that light pack-ice areas and polynias north and east of Pointe Géologie had extended (Fig. 1b). This resulted in better water access for departing males. The development of an eastward polynia and its exploitation by post-incubating males (one male in our study, Fig. 1b) concur with previous observations (Ancel et al. 1992) implying similar foraging conditions for penguins between years. Foraging trip durations of 19 and 29 days for both studied males, however, seem long compared to the 7-21 days recorded at Pointe Géologie by Ancel et al. (1992).

\section{Foraging zones}

The three females foraged intensively over a submarine plateau of about $200 \mathrm{~m}$ water depth as well as in areas of complex bathymetry with slopes ranging to more than $500 \mathrm{~m}$ water depth (depth data derived from ETOPO1). Complex bathymetry is often associated with upwelling, nutrient enrichment and thus high biological productivity, which may explain our data. The two males foraged in similar areas, whereas one male also foraged in a more distant (eastward) polynia. The higher incidence of deeper dives ( $>200 \mathrm{~m}$ ) for males (44 vs. $27 \%$ for females) may have provided access to different prey such as krill, that has been suggested to inhabit areas deep in the water column during the late winter period (Wienecke and Robertson 1997).

Spring (chick provisioning)

\section{Movement at sea}

During late chick-rearing in October and November the sea-ice extent decreased rapidly until there was free seawater access close to the colony in mid November.
Foraging in ice-free waters at distances far greater from the colony does not seem to be beyond the penguin capabilities. However, the present study shows that during the late chick-rearing period all 10 penguins confined their foraging activities to within $163 \mathrm{~km}$ of Pointe Géologie over the Antarctic shelf between 139 and $143^{\circ} \mathrm{E}$, rarely exceeding the shelf break. This foraging pattern in a "central place forager" suggests that there was sufficient food availability close to the breeding site. Foraging duration of trips between 31 October and 17 December $(7 \pm 1$ day) in this study roughly corresponded to the average durations of 9 days in early, and 7 days in late, November for penguins from Auster and Taylor Glacier (Kirkwood and Robertson 1997a). They were, however, only half those averaging 15 days in November for penguins from Coulman Island (Kooyman and Kooyman 1995). However, birds in this latter study moved between 81 and $859 \mathrm{~km}$ during a single of these short foraging trips (Table 1).

\section{Foraging zones}

The specific sites at which birds foraged during chickrearing should have been a trade-off between the constraints of the animal phenotype (dive capacities, fitness as function of parental care, chick requirements, etc.) and the food supply, which presumably varied with depth and distance from the colony. However, the foraging activities during both winter and spring were concentrated in similar locations (Fig. 9a, b) although the open sea access in the latter period should have enabled penguins to exploit the entire shelf area off Pointe Géologie (Fig. 6).

\section{Summer (pre-moult)}

In December, when the constraints of chick-rearing no longer applied and emperor penguins left the breeding colony, they headed beyond the coastal shelf break towards the 3,000-4,000 $\mathrm{m}$ deep ocean where they apparently travelled continuously rather than concentrating foraging effort in a particular area. Here, studied birds ventured at least $300 \mathrm{~km}$ north of the coast, reaching distances of up to $838 \mathrm{~km}$ to the colony (Table 1). This foraging pattern was similar to those of pre-moult foraging penguins studied at the Mawson Coast, although some birds also foraged in dense pack-ice close to their colony (Wienecke et al. 2004). We did not observe this pattern.

Our study identified two moulting locations in the residual pack-ice east and west of the Pointe Géologie colony (Figs. 6, 7). The eastern pack-ice area was proposed as a potential moulting location by Kooyman et al. (2000) who based findings on predictable late-season pack-ice. 
(a)

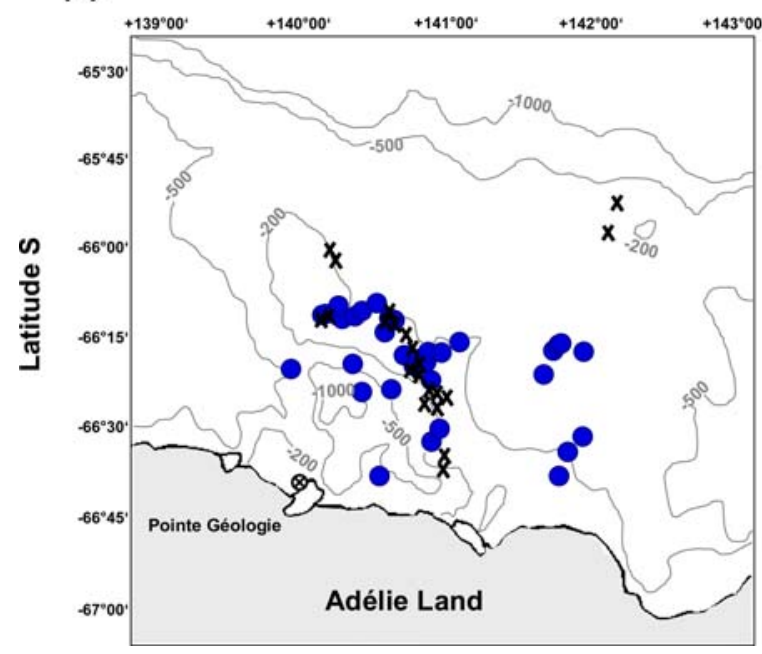

Fig. 9 Satellite locations of high catch per unit effort (CPUE, dots) and area-restricted-search index (ARS-I, cross) over the Antarctic shelf of monitored emperor penguins in a winter ( $n=5$ birds) and $\mathbf{b}$ spring ( $n=4$ birds). Locations were marked when CPUE and ARS-I

\section{Foraging zones}

Pre-moult trips of up to $3,686 \mathrm{~km}$ (Table 1) did not simply represent a direct transit to moult locations in the residual pack-ice (see Figs. 6, 7). Oceanic foraging over such a great radius off the shelf, as observed in our study and by Wienecke et al. (2004), suggests that there is more lucrative food supply over deep water and/or an enhanced opportunity to encounter prey by covering longer horizontal distances. The penguins offshore diet presumably relied on pelagic fish such as myctophid species or on Antarctic krill, Euphausia superba. Both of these were identified as a main pre-moult prey source for offshore feeding penguins in the eastern Ross Sea (Kooyman et al. 2004).

\section{Commonalities and restrictions in foraging patterns}

Since emperor penguins are sedentary birds returning to their traditional breeding site every year (Isenmann and Jouventin 1970; Isenmann 1971), they can be classed as central place foragers (Orians and Pearson 1979), although the duration that can be allocated to foraging varies greatly according to the time of year. These birds have essentially three major periods during the year, which have substantially different lengths of trips; (1) the moult period, when penguins leave the colony for a pre-moult foray lasting 3-7 weeks (this study, Wienecke et al. 2004), before moulting (ca. 4 weeks-Le Maho et al. 1976; Groscolas 1978), this being finally followed by a post-moult period

\section{Longitude $E$}

(b)

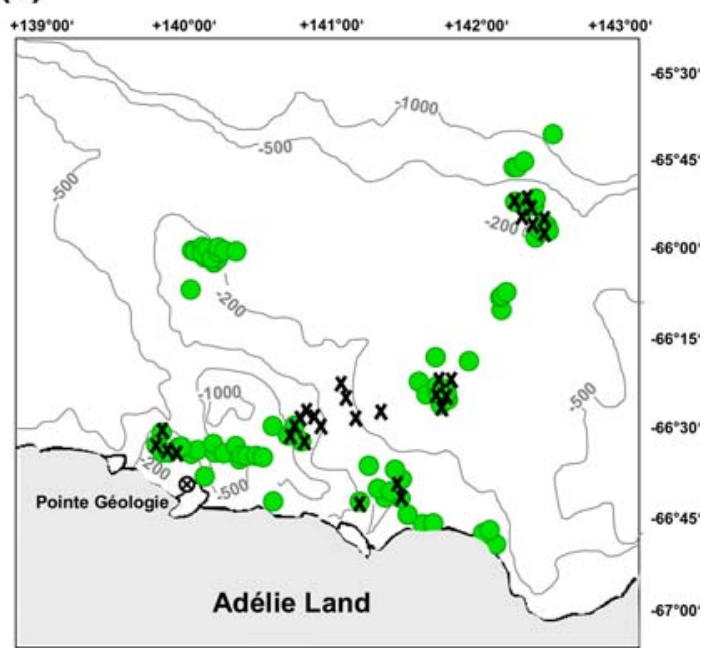

values of single foraging trips exceeded $60 \%$ of the individual parameter maximum (see Fig. 4b, c). Shelf bathymetry was derived from the ETOPO1 min gridded evaluation database (GEBCO 1-min global bathymetric grid)

(approximately one month), (2) the incubation period, lasting about 65 days (Prévost 1961; Isenmann 1971), which is only used by the females and (3) the chick-provisioning period, where forays away from the colony last between 2 days and several weeks depending on chick age (Mougin 1966; Isenmann 1971). As the time away from the central place increases, so too, does the potential for greater ranging movements. Indeed, it has been pointed out that even migration routes during the non-breeding season can be viewed as a particular form of foraging trip (Wilson et al. 2005) since all trips ultimately serve to enhance adult lifetime reproductive success. However, it is not necessarily of benefit to the foraging bird to spend extended time periods away from the central place at increasingly distant locations. This is because, although the Ashmole's halo effect will tend to result in a reduced prey density in close proximity of the colony due to intra-specific competition (Birt et al. 1987), this effect will become negated, and ultimately irrelevant, with the exponentially increasing search area with linearly increasing distance to the colony. Thus, when time permits, penguins should be seeking feeding (and living) conditions that allow them to maximize the net energy gain per unit time spent away from their central place (Mori 1998; Weimerskirch 1998; Ropert-Coudert et al. 2004). Although there is likely to be only one best solution to this under any given conditions, birds have to modulate their behaviour so that they fare best in an environment where they have imperfect information.

Typically, animals searching for food from a central place have an initial period of rapid travel away from the 
central place (Jouventin et al. 1994). In most penguins, this occurs by swimming, where prey might, theoretically, be encountered at any time (Wilson 1995). The highly variable ice cover encountered by emperor penguins over the course of the year, however, has a profound effect on when, and how, foraging might occur. During winter, when the females go foraging during the incubation period, the sea ice edge is ca. $400 \mathrm{~km}$ distant from the colony. This distance, coupled with a slow walk (Pinshow et al. 1977) to reach it, appears to make attempts to reach the open sea untenable at this time. Rather, the birds apparently use small holes and cracks in the ice to access the water, and exploit prey in the immediate vicinity of them. Increasing distance swum by penguins tends to increase the likelihood of prey capture (e.g. Wilson 1985). Thus, in order to mitigate against probable space constrictions by having to return to their particular breathing sites, females apparently engage in highly tortuous tracks underwater, which should serve to increase the underwater distance travelled (see results). The constraints imposed by the position of breathing locations in the ice, which need not necessarily correspond to regions of high prey density, may also explain why it is that the CPUE of these birds is lower than at any other time of the year. Presumably, the wandering movements of the females over the ice during the incubation period reflect movements between ice holes as prey in particular vicinities become depleted.

By the time that the males go on their first foraging trip following incubation, the ice cover has broken down enough to expose larger cracks and polynias which appear to be an important site for food for these birds (Ancel et al. 1992). Such conditions, though spatially constrained, have much greater expanses of open water and likely allow penguins to concentrate their foraging at sites where prey concentration is highest.

The recession of the ice edge as spring and summer advance increases the area of open sea in the vicinity of the colony. This removes the limitations of ice cover and decreases travelling time between foraging and breeding sites and is appropriate for the feeding frequency of the brood. Interestingly though, the birds at this time still appear to exploit approximately the same areas as those used by penguins during the winter and early spring (Fig. 9a, b). This would augur for particular features of that area, which result in high prey abundance (see above). The relaxation of access to the water due to the removal of ice cover, however, means that area-restricted-search can increase (Fig. 5a), allowing late chick-rearing penguins to conduct shorter efficient foraging trips in a period when food demand of the offspring is high.

Pre-moult birds are the only group to move to a distinct foraging area, which is much farther offshore than at other times of the year. The extended time that penguins spend away from the colony around the moult period, coupled with potentially particular conditions necessary for a successful moult on the ice (Kooyman et al. 2004), apparently make it more profitable for these birds to move out of the normal foraging zone being used during the breeding period. The pre-moult period is critical for penguins since food has to be acquired at a high rate to ensure that body condition is good enough to take the birds through the extended fast (Adams and Brown 1990) which must occur at a well-defined period of the year. We speculate that the foraging areas used by emperor penguins during the premoult period are characterized by particularly high prey abundance. However, the distance between these sites and the colony precludes them as foraging sites for penguins at other times of the year due to the extended time and energy necessary to access this zone.

Acknowledgments Fieldwork was logistically supported by the Institut Polaire Français Paul-Émile Victor (IPEV) and the Terres Australes and Antarctiques Françaises (TAAF). We thank the members of the 54th and 55th mission in Dumont durville, and in particular our colleagues T. Raclot and A. Dervaux for their help in the field, H. Bornemann for helping with the preparation of satellite transmitters and perpetual advice and G. Rohardt for providing the software to present the satellite tracks of studied penguins. This study was approved by the Ethics committee of the French Polar Institute.

\section{References}

Adams NJ, Brown CR (1990) Energetics of moult in penguins. In: Davis LS, Darby JT (eds) Penguin biology. Academic, San Diego, pp 297-315

Ancel A, Kooyman GL, Ponganis PJ, Gendner JP, Lignon J, Mestre X, Huin N, Thorson PH, Robisson P, Le Maho Y (1992) Foraging behavior of emperor penguins as a resource detector in winter and summer. Nature 360:336-339

Austin D, Bowen WD, McMillan JI, Iverson SJ (2006) Linking movement, diving, and habitat to foraging success in a large marine predator. Ecology 87(12):3095-3108

Bannasch R, Wilson RP, Culik B (1994) Hydrodynamic aspects of design and attachment of a back-mounted device in penguins. $\mathrm{J}$ Exp Biol 194:83-96

Birt VL, Birt TP, Goulet D, Cairns DK, Montevecci WA (1987) Ashmole's halo: direct evidence for prey depletion by a seabird. Mar Ecol Prog Ser 40:205-208

Bost CA, Handrich Y, Butler PJ, Fahlman A, Halsey LG, Woakes AJ, Ropert-Coudert Y (2007) Changes in dive profiles as an indicator of feeding success in king and Adélie penguins. Deep Sea Res II $54: 248-255$

Chappell MA, Shoemaker VH, Janes DN, Bucher TL, Maloney SK (1993) Diving behavior during foraging in breeding Adélie penguins. Ecology 74:1204-1215

Culik BM, Wilson RP, Bannasch R (1994) Underwater swimming at low energetic cost by Pygoscelid penguins. J Exp Biol 197:6578

Georges JY, Guinet C, Jouventin P, Weimerskirch H (1997) Satellite tracking of seabirds: interpretation of activity pattern from the frequency of satellite location. Ibis 139:403-405

Groscolas R (1978) Study of moult fasting followed by an experimental forced fasting in the emperor penguin Aptenodytes 
forsteri: relationship between feather growth, body weight loss, body temperature and plasma fuel levels. Comp Biochem Physiol 61A:287-295

Hull CL (2000) Comparitive diving behaviour and segregation of the marine habitat by breeding royal penguins, Eudyptes schlegeli, and eastern rockhopper penguins, Eudyptes chrysocome filholi, at Macquarie Island. Can J Zool 78:333-345

Isenmann P (1971) Contribution à léthologie et à lécologie du manchot empereur à la colonie de Pointe Géologie. Oiseau Rev Fr Ornithol 41:9-64

Isenmann P, Jouventin P (1970) Eco-éthologie du manchot empereur (Aptenodytes forsteri) en comparaison avec le manchot Adélie (Pygoscelis adeliae) et le manchot royal (Aptenodytes patagonica). ĹOiseau et la R F O 40:136-159

Jaquet N, Whitehead H (1999) Movements, distribution and feeding success of sperm whales in the Pacific Ocean, over scales of days and tens of kilometers. Aquat Mamm 25:1-13

Jouventin P (1982) Visual and vocal signals in penguins, their evolution and adaptive characters. In: Parey P (ed) Advances in ethology, Berlin, pp 149

Jouventin P, Capdeville D, Cuenot-Chaillet F, Boiteau C (1994) Exploitation of pelagic resources by a non-flying seabird: satellite tracking of the king penguin thoughout the breeding season. Mar Ecol Prog Ser 106:11-19

Kirkwood R, Robertson G (1997a) Seasonal change in the foraging ecology of emperor penguins on the Mawson Coast, Antarctica. Mar Ecol Prog Ser 156:205-223

Kirkwood R, Robertson GG (1997b) The foraging ecology of female emperor penguins in winter. Ecol Monogr 67:155-176

Kooyman GL, Cherel Y, Le Maho Y, Croxall JP, Thorson PH, Ridoux V (1992a) Diving behavior and energetics during foraging cycles in king penguins. Ecol Monogr 62:143-163

Kooyman GL, Hunke EC, Ackley SF, Van Dam RP, Robertson G (2000) Moult of the emperor penguin: travel, location, and habitat selction. Mar Ecol Prog Ser 204:269-277

Kooyman GL, Kooyman TG (1995) Diving behavior of emperor penguins nurturing chicks at Coulman Islan, Antarctica. The Condor 97:536-549

Kooyman GL, Ponganis PJ, Castellini MA, Ponganis EP, Ponganis KV, Thorson PH, Eckert SA, Le Maho Y (1992b) Heart-rates and swim speeds of emperor penguins diving under sea ice. $\mathrm{J}$ Exp Biol 165:161-180

Kooyman GL, Siniff DB, Stirling I, Bengston JL (2004) Moult habitat, pre- and post-moult diet and post-moult travel of Ross Sea emperor penguins. Mar Ecol Prog Ser 267:281-290

Le Maho Y, Delclitte P, Chatonnet J (1976) Thermoregulation in fasting emperor penguins under natural conditions. Am J Physiol 231:913-922

Leopold MF, VanElk JF, VanHeezik YM (1996) Central place foraging in oystercatchers Haematopus ostralegus: Can parents that transport mussels Mytilus edulis to their young profit from size selection? Ardea 84 A:311-325

Luna-Jorquera G, Culik BM (1999) Diving behaviour of Humboldt penguins (Spheniscus humbolti) in nothern Chile. Mar Ornithol 27:67-76

Markman S, Pinshow B, Wright J, Kotler BP (2004) Food patch use by parent birds: to gather food for themselves or for their chicks? J Anim Ecol 73:747-755

Meinertzhagen R (1955) The speed and altitude of bird flight. Ibis 97:21-25

Mori Y (1998) The optimal patch use in divers: optimal time budget and the number of dive cycles during bout. J Theoret Biol 190:187-199

Mougin J-L (1966) Observations écologiques à la colonie de manchots empereurs de Pointe Gélologie (Terre Adélie) en 1964. Oiseau Rev Fr Ornithol 36(3-4):166-226
Nolet BA, Mooij WM (2002) Search paths of swans foraging on spatially autocorrelated tubers. J Anim Ecol 71:451-462

Offredo C, Ridoux V (1986) The diet of emperor penguins Aptenodytes forsteri in Adélie Land, Antarctica. Ibis 128:409-413

Orians GH, Pearson NE (1979) On the theory of central place foraging. In: Horn DJ, Mitchell R, Stair GR (eds) Analysis of ecological systems. Ohio State University Press, Columbus, pp 155-177

Pinshow B, Fedak MA, Schmidt-Nielsen K (1977) Terrestrial locomotion in penguins: it costs more to waddle. Science 195:592-594

Prévost J (1961) Ecologie du manchot empereur. Expéditions Polaires Francaises. Hermann Press, Paris, p 204

Robertson GG, Newgrain K (1996) The food and energy intake rates of adult emperor penguins (Aptenodytes forsteri) rearing chicks. Antarct Sci 8(1):37-44

Robisson P (1992) Vocalizations in Aptenodytes penguins: application of the two-voice theory. Auk 109(3):654-658

Rodary D, Bonneau W, Le Maho Y, Bost CA (2000a) Benthic diving in male emperor penguins Aptenodytes forsteri foraging in winter. Mar Ecol Prog Ser 207:171-181

Rodary D, Wienecke BC, Bost C-A (2000b) Diving behaviour of Adélie penguins (Pygoscelis adéliae) at Dumont D́Urville, Antarctica: nocturnal patterns of diving and rapid adaptations to changes in sea-ice condition. Polar Biol 23:113-120

Ropert-Coudert Y, Kato A, Wilson RP, Cannell B (2006) Foraging strategies and prey encounter rate of free-ranging little penguins. Mar Biol 149:139-148

Ropert-Coudert Y, Wilson RP (2005) Trends and perspectives in animal-attached remote-sensing. Frontiers Ecol Environ 3(8):437-444

Ropert-Coudert Y, Wilson RP, Daunt F, Kato A (2004) Patterns of energy acquisition by a central place forager: benefits of alternating short and long foraging trips. Behav Ecol 15:824-830

Simeone A, Wilson RP (2003) In depth studies of Magellanic penguin (Spheniscus magellanicus) foraging: can we estimate prey consumption by perturbations in the dive profile? Mar Biol 143:825-831

Takahashi A, Dunn MJ, Trathan PN, Croxall JP, Wilson RP, Sato K, Naito Y (2004) Krill-eating behaviour in a chinstrap penguin (Pygoscelis Antarctica) compared with fish-eating in magellanic penguins (Spheniscus magellanicus): a pilot study. Mar Ornithol 32:7-54

Tremblay Y, Cherel Y (2000) Benthic and pelagic dives: a new foraging behaviour in rockhopper penguins. Mar Ecol Prog Ser 204:257-267

Weimerskirch H (1998) How can a pelagic seabird provision its chick when relying on a distant resource? Cyclic attendance, foraging decision and body condition in sooty shearwaters. J Anim Ecol 67:99-109

Weimerskirch H, Chastel O, Chaurand T, Ackerman L, Hindermeyer X, Judas J (1994a) Alternate long and short foraging trips in pelagic seabird parent. Anim Behav 47:472-476

Weimerskirch H, Doncaster CP, Cuenot-Chaillet F (1994b) Pelagic seabirds and the marine environment: foraging patterns of wandering albatrosses in relation to prey availability and distribution. Proc R Soc Lond B 255:91-97

Wienecke B, Kirkwood R, Robertson G (2004) Pre-moult foraging trips and moult locations of emperor penguins at the Mawson Coast. Polar Biol 27:83-91

Wienecke B, Robertson GG, Kirkwood R, Lawton K (2007) Extreme dives by free-ranging emperor penguins. Polar Biol 30(2):133-142

Wienecke BC, Robertson GG (1997) Foraging space of emperor penguins Aptenodytes forsteri in Antarctic shelf waters in winter. Mar Ecol Prog Ser 159:249-263

Williams TD (1995) The penguins. Bird families of the world. Oxford University Press, Oxford, p 295 
Wilson RP (1985) The jackass penguin Spheniscus demersus as a pelagic predator. Mar Ecol Prog Ser 25:219-227

Wilson RP (1995) Foraging ecology. In: Williams TD (ed) The penguins. Bird families of the world. Oxford University Press, Oxford, pp 81-106

Wilson RP (2002) Movements in Adélie penguins foraging for chicks at Ardley Island, Antarctica; circles within spirals, wheels within wheels. Polar Biosci 15:75-87

Wilson RP, Nagy KA, Obst B (1989) The foraging range of penguins. Polar Rec 25:303-307

Wilson RP, Pütz K, Charrassin JB, Lage J (1995) Artifacts arising from sampling interval in dive depth studies of marine endotherms. Polar Biol 15:575-581
Wilson RP, Pütz K, Peters G, Culik B, Scolaro JA, Charrassin JB, Ropert-Coudert Y (1997) Long-term attachment of transmitting and recording devices to penguins and other seabirds. Wildl Soc Bull 25:101-106

Wilson RP, Ropert-Coudert Y, Kato A (2002) Rush and grab strategies in foraging marine endotherms: the case for haste in penguins. Anim Behav 63:85-95

Wilson RP, Scolaro JA, Grémillet D, Kierspel MAM, Laurenti S, Upton J, Gallelli H, Quintana F, Frere E, Müller G, Thor Straten M, Zimmer I (2005) How do magellanic penguins cope with variability in their access to prey? Ecol Monogr 75(3):379-401 